\title{
Diagnóstico e tratamento das assimetrias dentofaciais
}

\author{
João Luiz Carlini*, Kelston Ulbricht Gomes**
}

\begin{abstract}
Resumo
A assimetria facial é uma característica humana comum, que muitas vezes não é notada pelo próprio paciente nem pelas pessoas com quem ele convive. Entretanto, ela se torna relevante quando o próprio paciente relata alguma alteração. A avaliação profissional deve ser requisitada para que a etiologia seja estabelecida através de diversos métodos de diagnóstico. A deformidade poderá decorrer de fatores genéticos, como encontrado em pacientes portadores de microssomia hemifacial, ou adquirida em traumas e patologias. O tratamento das assimetrias faciais tem como objetivo um resultado estético satisfatório e, principalmente, estabilidade oclusal e funcional. O plano de tratamento é elaborado de acordo com a etiologia, a severidade da deformidade, a idade do paciente e as áreas afetadas, corrigindo a deformidade instalada ou impedindo sua evolução. O propósito deste trabalho é revisar a literatura no que diz respeito à etiologia, métodos de diagnóstico e às formas de tratamento das assimetrias faciais, exemplificando com casos clínicos as diferentes formas de abordagem das assimetrias.
\end{abstract}

Palavras-chave: Cirurgia. Assimetria facial. Tratamento.

\section{INTRODUÇÃO}

Considerando que todas as faces são assimétricas, o que determinará a necessidade de tratamento é a questão estética relatada pelo paciente, a importância clínica com relação à estabilidade oclusal e a etiologia da deformidade.

Uma vez identificado o problema, deve-se avaliar as áreas da face afetadas, a intensidade da deformidade, interceptar a evolução ou corrigir a deformidade já instalada, buscando um resultado que ofereça estética, função e estabilidade.

A definição da etiologia da assimetria, seja ge- nética, patológica ou traumática será fundamental para a orientação do plano de tratamento. Os métodos de diagnóstico são decisivos no planejamento, principalmente no que se refere às estruturas atingidas, pois há limitações da Ortodontia e da Cirurgia, em virtude da complexidade de estruturas anatômicas envolvidas, sendo necessário variações das técnicas em casos específicos.

\section{FATORES ETIOLÓGICOS}

As assimetrias craniofaciais podem ser divididas em fatores de origem genética e adquiridas.

\footnotetext{
* Universidade Federal do Paraná - UFPR; CAIF - Centro de Atendimento Integral ao Fissurado Lábio Palatal. Professo Adjunto de Cirurgia I da Universidade Federal do Paraná. Staff do Serviço de Cirurgia Bucomaxilofacial do CAIF.

** Cirurgião Dentista formado pela Universidade Federal do Paraná em 2002. Estagiário do Serviço de Cirurgia BucomaxiCirurgião Dentista
lofacial do CAlF.
} 
Geneticamente são provocadas pela interrupção da proliferação e do desenvolvimento celular, acarretando no desenvolvimento da deformidade. A microssomia hemifacial, segundo Vargervik ${ }^{17}$, é uma das mais freqüentes anomalias craniofaciais, caracterizada pela má formação do pavilhão auricular, envolvimento do osso temporal, incluindo a falta da fossa mandibular e ausência de estruturas articulares côndilos e processos coronóides. Cho et al. ${ }^{2}$, observaram que esses pacientes apresentavam movimentos mandibulares restritos como conseqüência da falta de estruturas articulares.

Nas assimetrias adquiridas ou de desenvolvimento, várias são as causas que levam à assimetria facial.

Fatores patológicos, como a anquilose da articulação temporomandibular (ATM), citada por Yoon e $\mathrm{Kim}^{18}$ é a grande causadora de deformidades como retrognatismo mandibular, desvios do mento para o lado afetado, limitação de movimentos mandibulares, atrofia dos músculos faciais. Além destes, lesões que atingem a ATM, como os osteocondromas, as hiperplasias, as hipoplasias e agenesias condilares e desordens intra-articulares associadas à artrose acabam gerando algum grau de assimetria. Outras causas incluem o parto à fórceps, infecção otológica e o uso inadequado de aparelhos ortopédicos.

Segundo Peterson et al. ${ }^{13}$, os traumas ocorridos na região craniofacial, podem desencadear anquilose da articulação têmporo-mandibular em crianças em fase de crescimento, como conseqüência da destruição da área de crescimento da cartilagem da ATM.

José Dahan ${ }^{4}$ faz uma observação importante quanto aos desvios mandibulares resultantes da própria intercuspidação dentária e contatos prematuros existentes, que podem acarretar desvios mandibulares posturais e conseqüentemente falsas assimetrias.

Todas estas situações podem gerar compensações dentárias e afetar tanto o crescimento da mandíbula quanto o crescimento da maxila, dificultando a resposta dos tecidos moles ao tratamento.

\section{DIAGNÓSTICO}

As informações colhidas sobre o paciente são importantíssimas no auxílio do diagnóstico da assimetria. O relato de traumas ocorridos, infecções otológicas, história familiar, o uso de aparelhos ortopédicos e quando foi percebido o problema são informações que colaborarão no diagnóstico.

$\mathrm{O}$ exame físico, segundo Yoon e $\mathrm{Kim}^{18}$ é realizado fazendo comparações entre as duas hemifaces, verificando diferenças de tamanho e forma. Observa-se também a presença de desvios mandibulares, limitação de abertura bucal e desvios do mento. Recomenda-se que o paciente esteja em posição ortostática. Benson e Laskin ${ }^{1}$ sugerem a utilização de espátulas de madeira, onde o paciente apreende entre os dentes a espátula e mensura-se a distância entre a espátula (na altura da comissura labial) até a linha interpupilar, diagnosticando clinicamente o envolvimento ou não da maxila na assimetria.

Peterson et al. ${ }^{13}$ enfatizaM que a avaliação deve incluir o osso frontal, os olhos, os rebordos infra-orbitários, as eminências zigomáticas, a configuração do nariz incluindo a largura da base alar, as áreas paranasais, a morfologia do lábio, o relacionamento dos lábios com os incisivos e todo o relacionamento proporcional da face nos sentidos vertical e transversal.

Os exames complementares são fundamentais no estabelecimento do diagnóstico definitivo, como preconizados por José Daham ${ }^{4}$. A radiografia panorâmica, a radiografia póstero-anterior (PA) de crânio e de mandíbula, a tomografia computadorizada em cortes coronais e axiais e a telerradiografia de perfil que auxilia no diagnóstico de desnivelamento da porção basilar da mandíbula.

Outros exames como a cintilografia com Tecnécio 99 é recomendada quando se suspeita de crescimento anormal no côndilo da mandíbula. Este exame apontará atividade celular no côndilo, ou a estabilização da atividade óssea no local, o resultado do exame irá interferir diretamente na conduta adotada. 
Nos casos severos com envolvimento do crânio, terço médio e inferior da face, são utilizados exames que reproduzam a estrutura óssea da face em um plano tridimensional. Segundo Ferrario et al. ${ }^{5}$, destacam os sistemas ótico-eletrônicos, os scanners a laser, digitadores eletromagnéticos e a reconstrução tridimencional (3D) de imagens (estereolitografia). Jens Kragskov et al. ${ }^{8}$ também sugerem a utilização da tomografia computadorizada com reconstrução em 3D.

\section{FORMAS DE TRATAMENTO}

O tratamento das assimetrias faciais é diferenciado conforme a idade do paciente, a área afetada e a sua etiologia.

Segundo Yoon e $\mathrm{Kim}^{18}$, para o tratamento da anquilose têmporo-mandibular é necessária a ressecção da anquilose, a prevenção de sua recidiva e o restabelecimento de uma oclusão funcional e harmoniosa.

A liberação da anquilose juntamente com enxerto costocondral continua sendo o procedimento preconizado. Entretanto, o enxerto costocondral está geralmente associado a problemas como um excesso de crescimento imprevisível ou até mesmo necrose e reabsorção do enxerto.

Em casos de hiperplasias condilares é necessário verificar se essa condição é estável ou não, sugere-se o exame de cintilografia com Tecnécio 99. Se for identificado foco de crescimento opta-se por realizar uma condilotomia alta, onde se remove somente a porção superior do côndilo. Este procedimento é válido para o paciente que já cessou a fase de crescimento ósseo fisiológico. Em pacientes adultos que apresentam deformidade anatômica severa e atividade celular no côndilo, sugere-se a remoção do côndilo, chamada condilectomia.

Os pacientes portadores de microssomia hemifacial, podem ser classificados em leve, moderado e severo. $O$ tratamento para o grupo leve geralmente é realizado após o período da puberdade, corrigido através de avanços mandibulares, mentoplastia ou aumento mandibular unilateral. Para pacientes do grupo moderado, um avanço rotacional da mandíbula com enxerto autógeno está indicado. Nos casos de microssomia severa a cirurgia de maxila, mandíbula e mento combinadas estão indicadas juntamente com enxertos autógenos, além das reconstruções plásticas do pavilhão auricular.

A distração osteogênica é uma alternativa de tratamento para as assimetrias. As vantagens desse tipo de tratamento são: a diminuição do tempo de cirurgia, a menor morbidade e a direção e a quantidade do alongamento de osso poderem ser controladas. É importante ressaltar que os tecidos moles, vasos e nervos adjacentes acompanham essa distensão progressiva da estrutura óssea, fato que não ocorre quando se utiliza o enxerto.

A distração osteogênica é um recurso moderno que se aplica para o tratamento de várias assimetrias como as causadas por anquilose têmporomandibular, microssomia hemifacial, hipoplasias de mandíbula e maxila e aquelas presentes em algumas síndromes.Como sugerido por Ortiz Monasterio et al. ${ }^{11}$, que propuseram a distração osteogênica simultânea de maxila e mandíbula no tratamento de microssomia hemifacial severa. Corcoran et $\mathrm{al}^{3}{ }^{3}$ fizeram uso da distração osteogênica para a reconstrução de ramo de mandíbula juntamente com enxerto costocondral. Para os casos de hipoplasia de zigoma, por exemplo, a osteodistração também está indicada segundo Cho et al. ${ }^{2}$

\section{CASUÍSTICA E TRATAMENTO}

As variações do tratamento são notadas nos casos clínicos, abaixo descritos.

\section{Caso 1}

Paciente J. A. M. S., 30 anos de idade, gênero feminino, apresentou-se no Serviço de Cirurgia Bucomaxilofacial do CAIF (Centro de Tratamento Integral ao Fissurado Lábio-Palatal, Curitiba - PR) com assimetria facial severa, conforme a figura 1 . Após o exame clínico foi solicitada radiografia pa- 
norâmica, terradiografia de perfil e póstero-anterior de mandíbula. A paciente apresentava fissura do processo alveolar unilateral do lado esquerdo, mordida aberta posterior do lado direito e ausência dos seguintes elementos dentários 16, 17, 18, 22, 24, 28, 36, 38, 47 e 48 (Fig. 2).
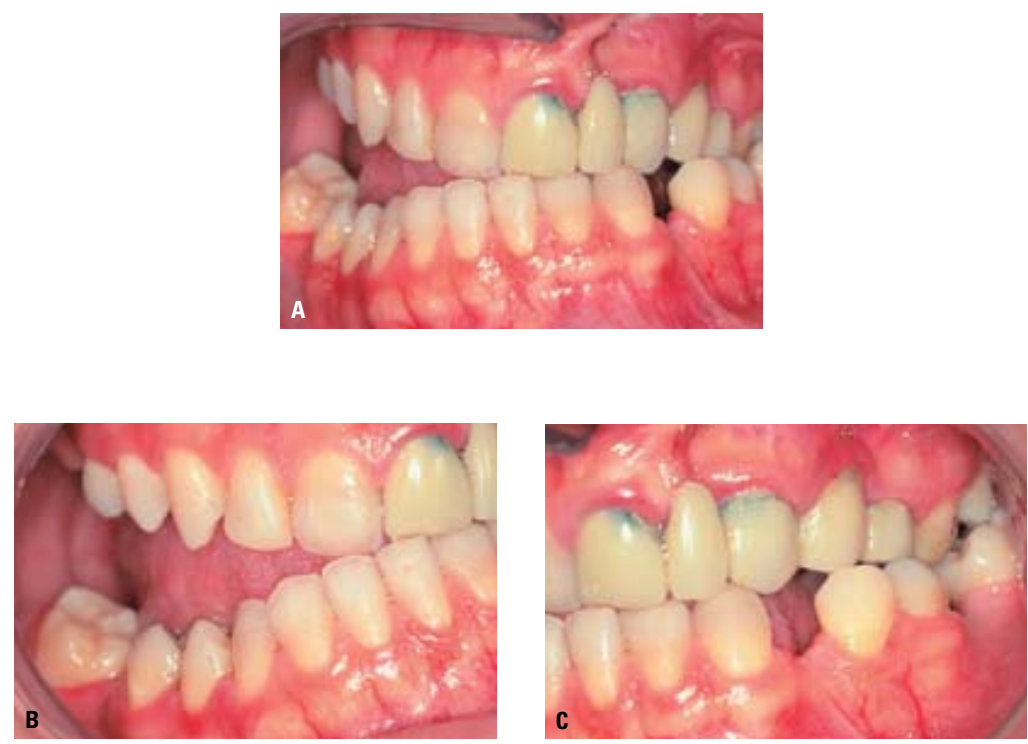

FIGURA 2 - Vista da oclusão pré-operatória. A) frontal, B) lateral direita, C) lateral esquerda.

FIGURA 1 - Vista frontal.
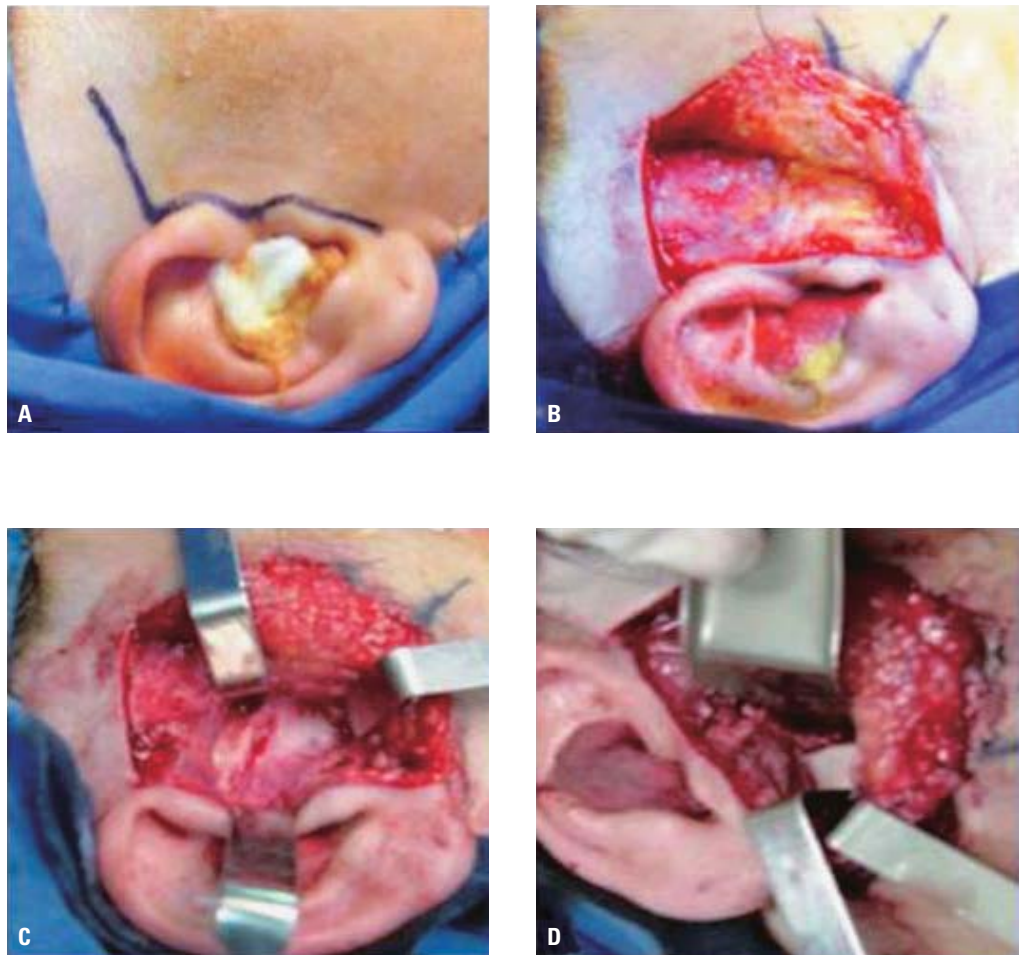

FIGURA 3 - Cirurgia de condilotomia. A) Desenho do acesso pré-auricular, B) Divulsão dos tecidos, C) Exposição da cápsula articular, D) Ressecção do côndilo. 
Observou-se ao exame radiográfico, que o côndilo do lado direito era anômalo em relação ao côndilo esquerdo, provocando, inclusive, desnivelamento da maxila. Foi sugerido exame de cintilografia óssea (TM-99), onde detectou-se atividade celular na cabeça do côndilo direito. Foi planejado, inicialmente, a expansão ortodôntica da maxila, restabelecendo o espaço da
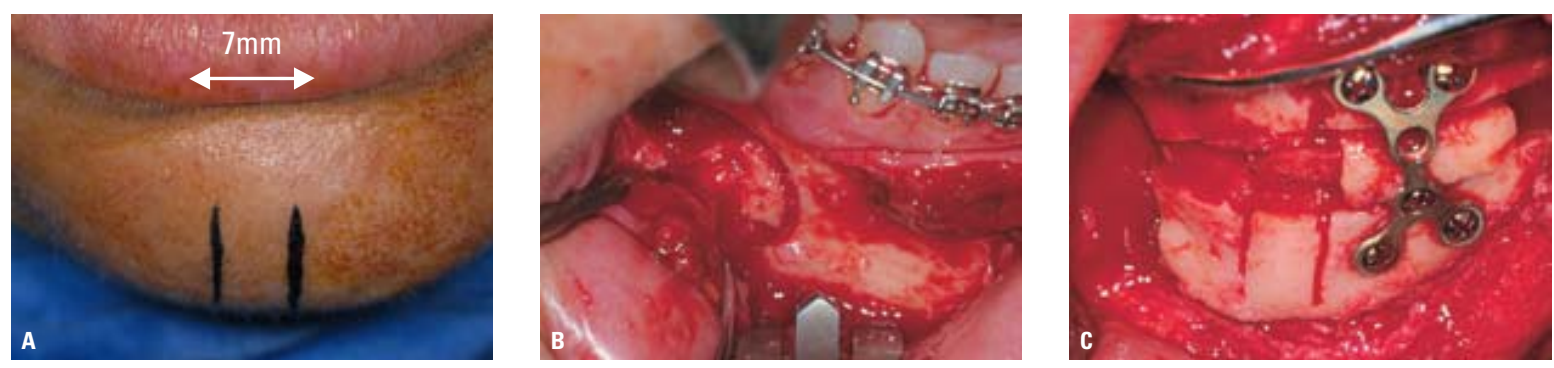

FIGURA 4 - Cirurgia de correção do mento e osso basilar da mandíbula. A) Vista frontal, evidenciando a diferença do desvio do mento (7mm para a esquerda), B) Osteotomia ao redor do forâme mentoniano para deslocar o nervo alveolar e possibilitar a remoção da porção basilar da mandíbula, C) Correção da linha média do mento com enxerto autógeno e fixação rígida.
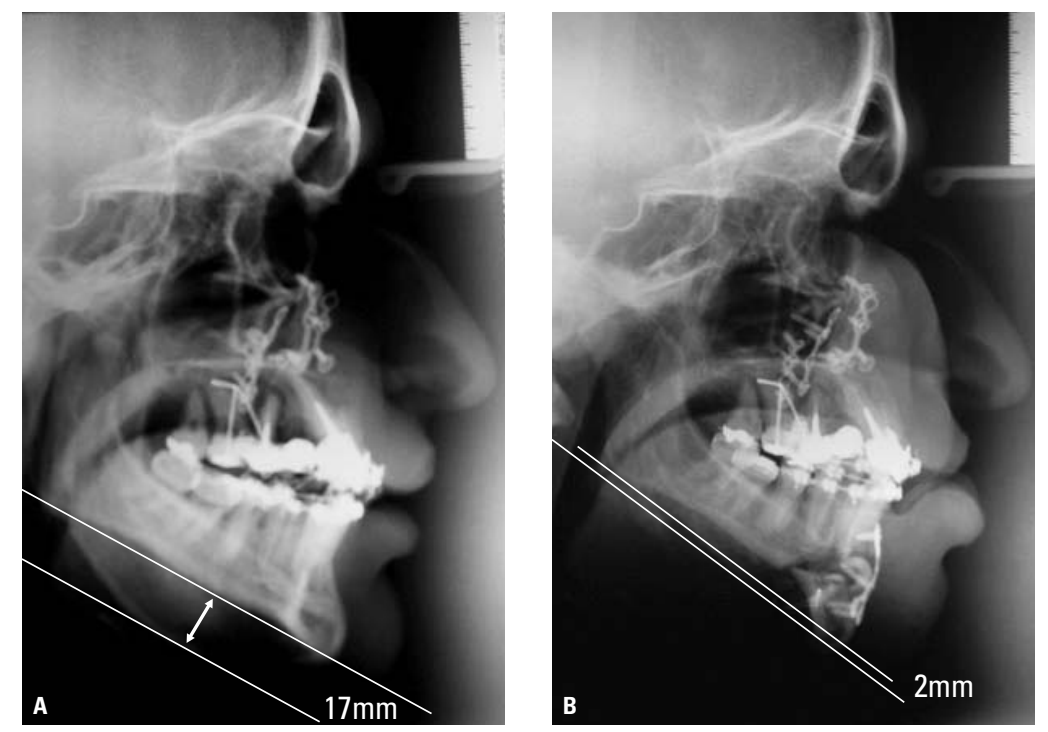

FIGURA 5 - A) Telerradiografia de perfil após a primeira intervenção, evidenciando a diferença das basilares da mandíbula, B) Telerradiografia após a segunda intervenção corrigindo a basilar da mandíbula.
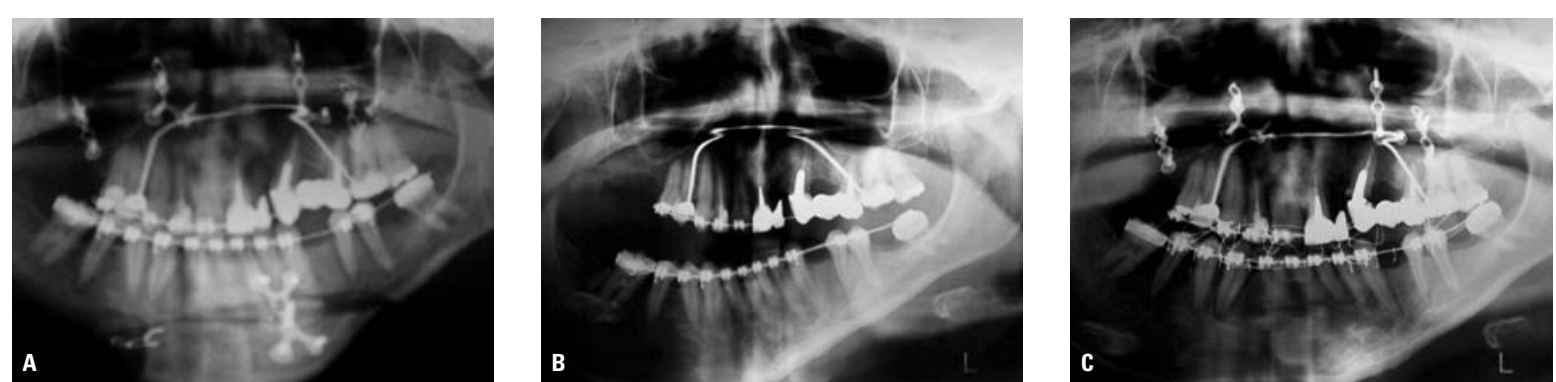

FIGURA 6 - A) Panorâmica pré-operatória, B) Panorâmica após primeira intervenção, C) Panorâmica após segunda intervenção. 

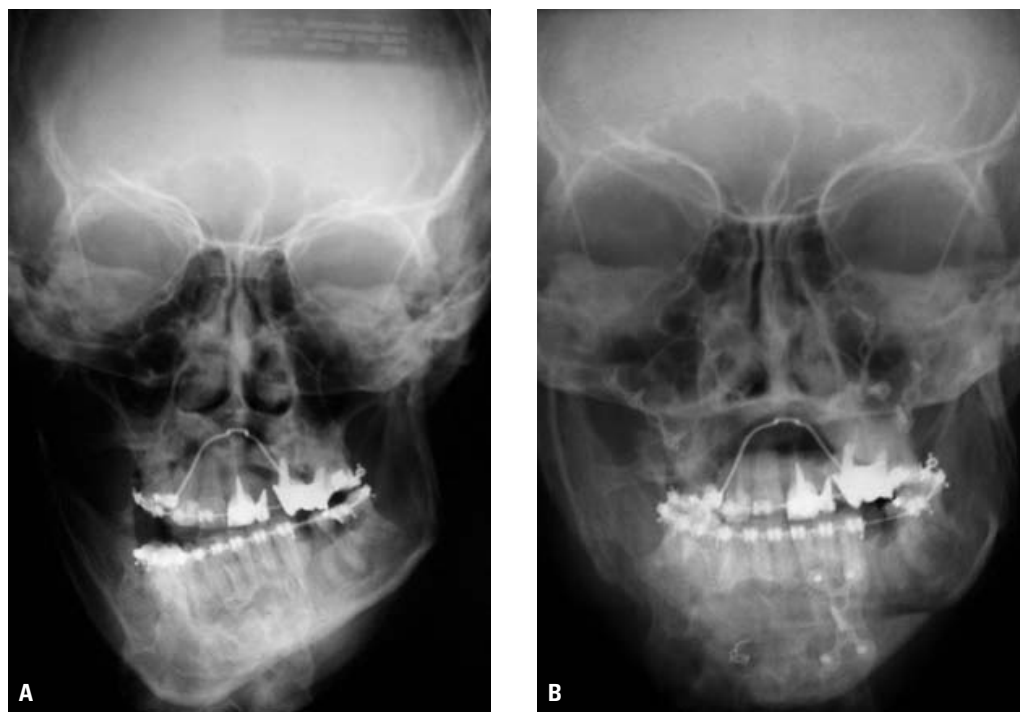

FIGURA 7 - A) Radiografia póstero-anterior pré-operatória, B) Radiografia póstero-anterior pós-operatória.
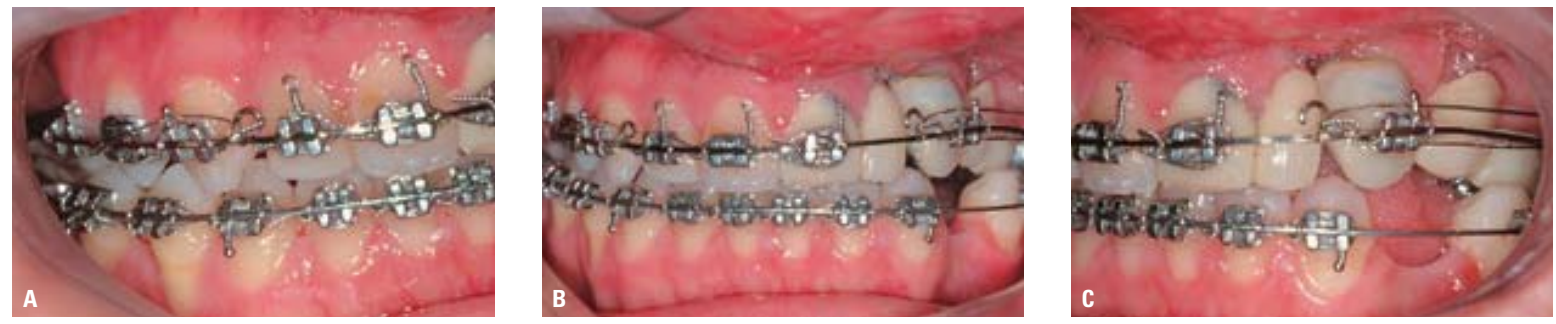

FIGURA 8 - Vista oclusal pós-operatória. A) vista lateral direita, B) Vista da oclusão frontal, C) Vista lateral esquerda.
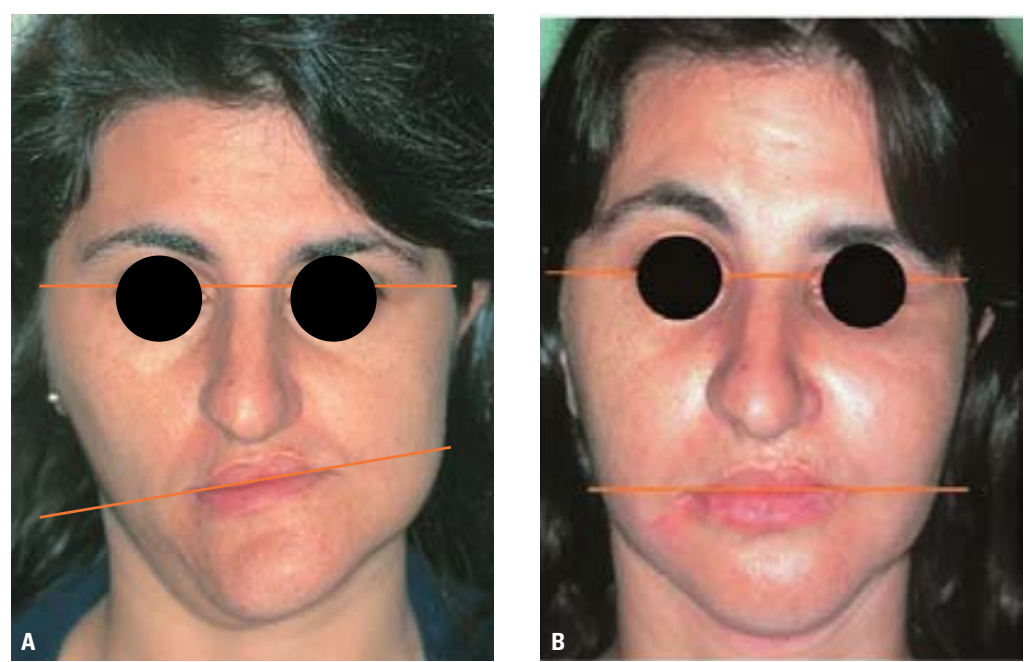

FIGURA 9 - Vista frontal da face. A) Vista pré-operatória, B) Vista pós-operatória. 
fissura com aparatologia ortodôntica fixa précirurgia ortognática. Planejou-se na primeira intervenção a condilotomia do lado direito (Fig. 3), osteotomia Le Fort I para o nivelamento da maxila e ostetomia vertical intrabucal bilateral da mandíbula. Na segunda fase, partiu-se para a correção do mento e da basilar do corpo da mandibula do lado direito. Com acesso intrabucal a partir da incisão da mentoplastia, estendendo até a região retromolar do lado direito. Iniciou-se pela ostetomia do mento e deslocamento do nervo alveolar inferior direito para a ostectomia da basilar da mandíbula, nivelandoa com o lado esquerdo. Em seguida, foi fixado o mento, com miniplaca e parafusos de titânio, e a "ilhota" de osso foi fixada com fio de aço ao novo mento posicionado (Fig. 4). A paciente apresentou parestesia por 8 meses do nervo alveolar inferior direito. Nas figuras 5 e 6 observase as mudanças ocorridas nas estruturas ósseas após a primeira intervenção e após a sengunda intervenção. Observa-se a melhora estética e funcional nas figuras 7,8 e 9 .

\section{Caso 2}

Paciente P.D., 27 anos de idade, gênero feminino, apresentou-se no Serviço de Cirurgia Bucomaxilofacial do CAIF (Centro de Tratamento Integral ao Fissurado Lábio-Palatal, Curitiba/PR) com assimetria facial severa, segundo figura 10 A, após o exame clínico foi solicitada radiografia panorâmica (Fig. 10B), terradiografia de perfil e

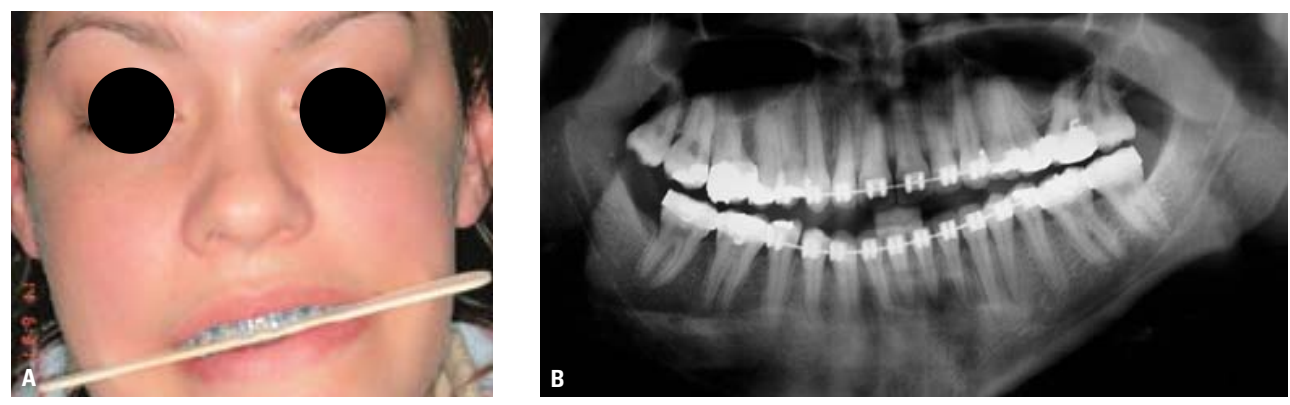

FIGURA 10 - A) Pré-operatório evidenciando o desnivelamento da maxila, B) Radiografia panorâmica pré-operatória.
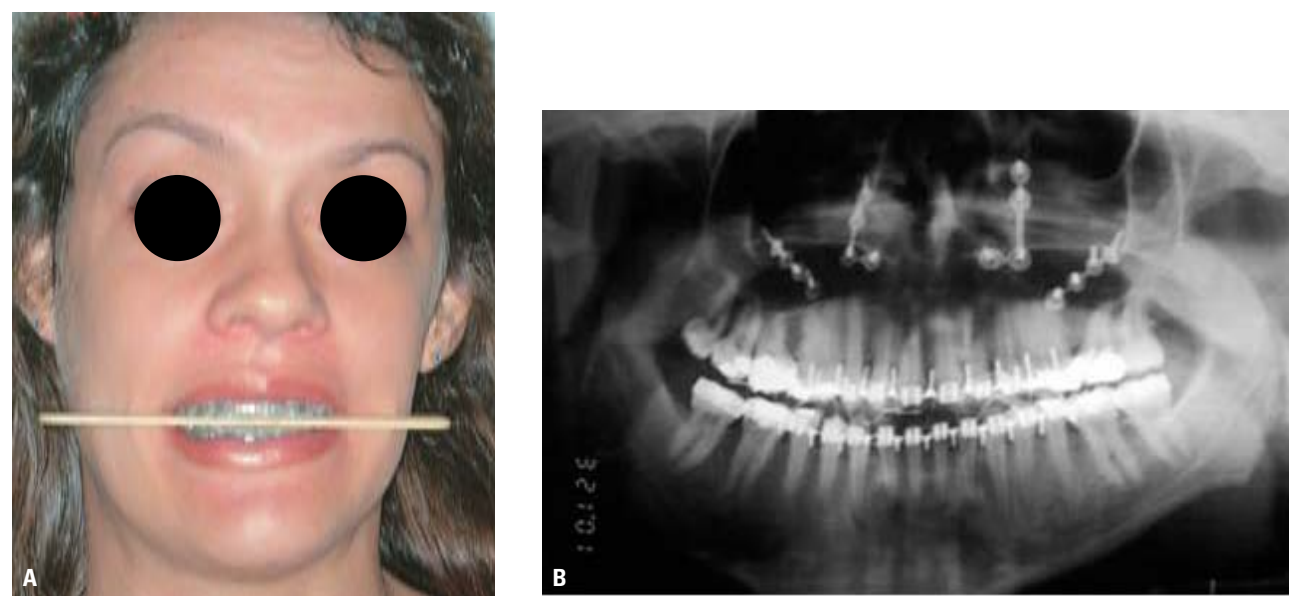

FIGURA 11 - A) Pós-operatório com o nivelamento do plano oclusal, B) Radiografia panorâmica pós-operatória. 

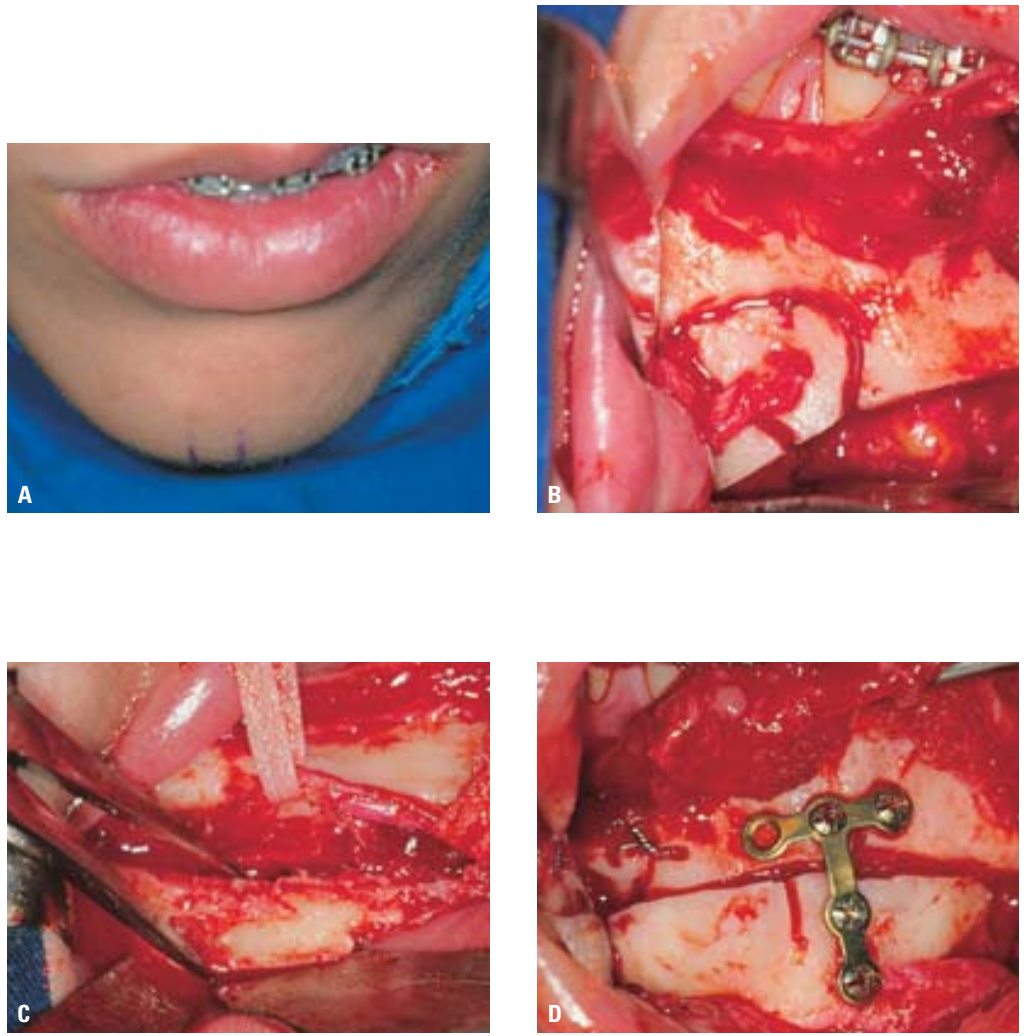

FIGURA 12 - A) Vista frontal do mento demonstrando o desvio do mento, B) Osteotomia em "ilha" do forâme mental para deslocamento do nervo alveolar, C) Remoção da porção basilar da mandíbula do lado afetado, D) Fixação com fio de aço da "ilha" de osso e fixação rígida do mento.
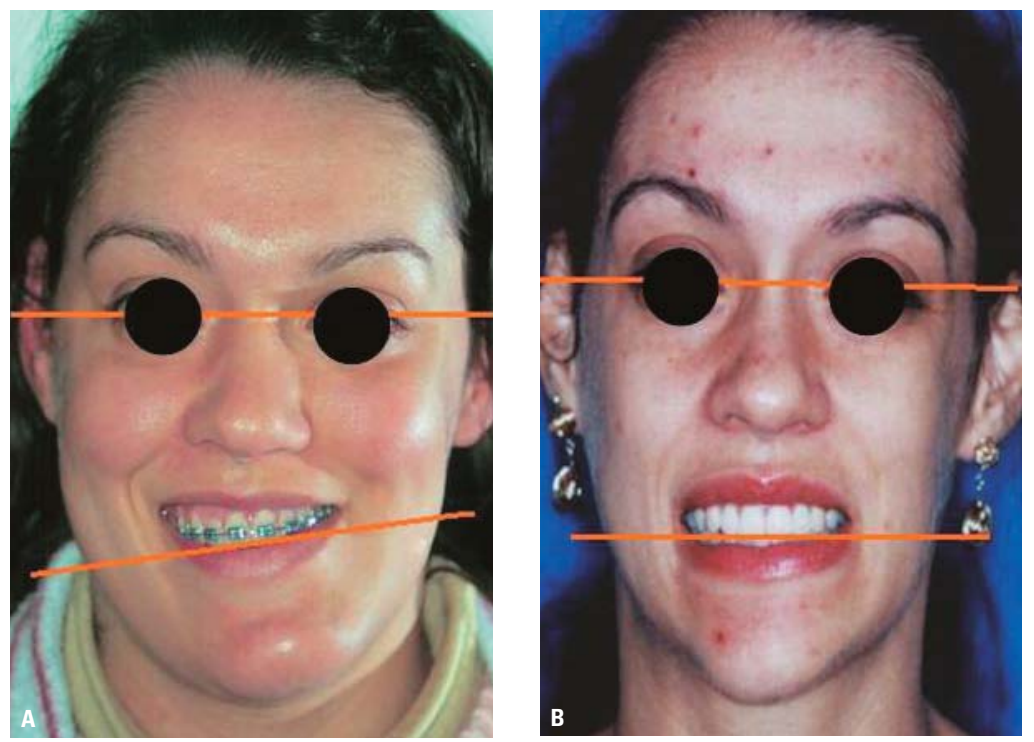

FIGURA 13 - A) Vista frontal pré-operatória evidenciando a exposição assimétrica da gengiva da maxila, B) Vista frontal pós-operatória. 
póstero-anterior de mandibula.

Ao exame radiográfico, o côndilo do lado direito apresentava-se anômalo em relação ao côndilo esquerdo. Foi realizada a cintilografia, onde não foi detectada atividade celular na cabeça do côndilo direito, portanto a intervenção não se justificava. A paciente já apresentava aparatologia ortodôntica fixa pré-cirurgia ortognática.

$\mathrm{Na}$ primeira intervenção foi realizada a osteotomia Le Fort I para corrigir o desnivelamento da maxila e ostetomia vertical intraoral bilateral da mandíbula (Fig. 11). Na segunda fase, o objetivo era a correção do mento e da basilar do corpo da mandíbula do lado direito. Com acesso intrabucal a partir da incisão da mentoplastia, estendeu-se até a região retromolar do lado direito. Realizou-se a ostetomia do mento e o deslocamento do nervo alveolar inferior direito para a osteotomia na basilar da mandíbula, nivelando-a com o lado esquerdo. Em seguida, foi fixado o mento com miniplaca e parafusos e a "ilhota" de osso fixada com fio de aço ao novo mento posicionado (Fig. 12). Observou-se a melhora estética e a correção do sorriso assimétrico da maxila (Fig. 13).

\section{Caso 3}

Paciente S. M., idade 37 anos de idade, gênero feminino, apresentou-se no serviço de Cirurgia Bucomaxilofacial do CAIF com assimetria facial e desvio para o lado esquerdo (Fig. 14), diagnosticado como hipodesenvolvimento do ramo mandibular do lado esquerdo (microssomia facial leve), causando desvio da linha média dentária inferior em relação à linha média dentária superior e linha média facial. Foi sugerida, como forma de tratamento, a instalação de distrator no ramo mandibular afetado (Fig. 15).

A cirurgia foi realizada com acesso intraoral, efetuando-se a osteotomia no terço médio do ramo mandibular e instalando-se o distrator. Devido à limitação da articulação do aparelho, a porção de ativação do aparelho ficou posicionada na região cutânea do ângulo mandibular (Fig. 16A). Permaneceu em latência por 7 dias, quando iniciamos a ativação de $0,4 \mathrm{~mm}$ por dia. Permanecendo estabilizado por 4 meses (Fig. 16B), quando nova cirurgia foi realizada para a remoção do aparelho e comprovou-se o resultado de $13 \mathrm{~mm}$ de distração óssea (Fig. 16C).

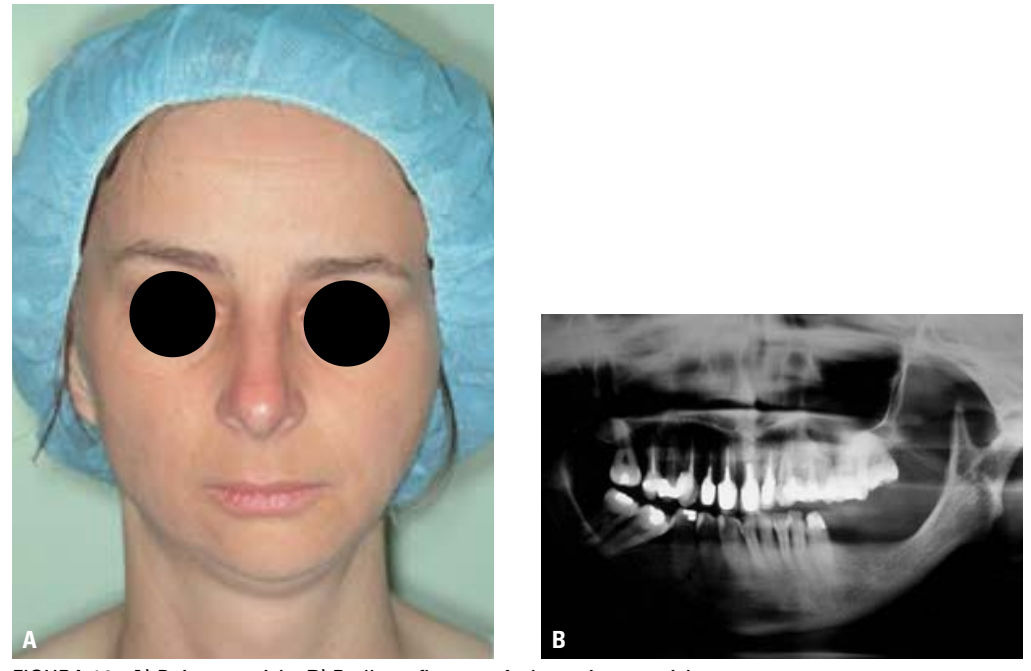

FIGURA 14 - A) Pré-operatório, B) Radiografia panorâmica pré-operatória.

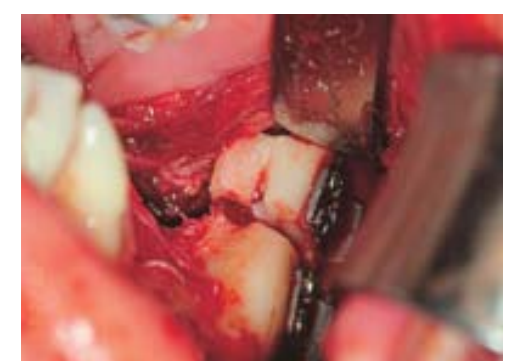

FIGURA 15 - Trans-operatório na instalação do distrator 

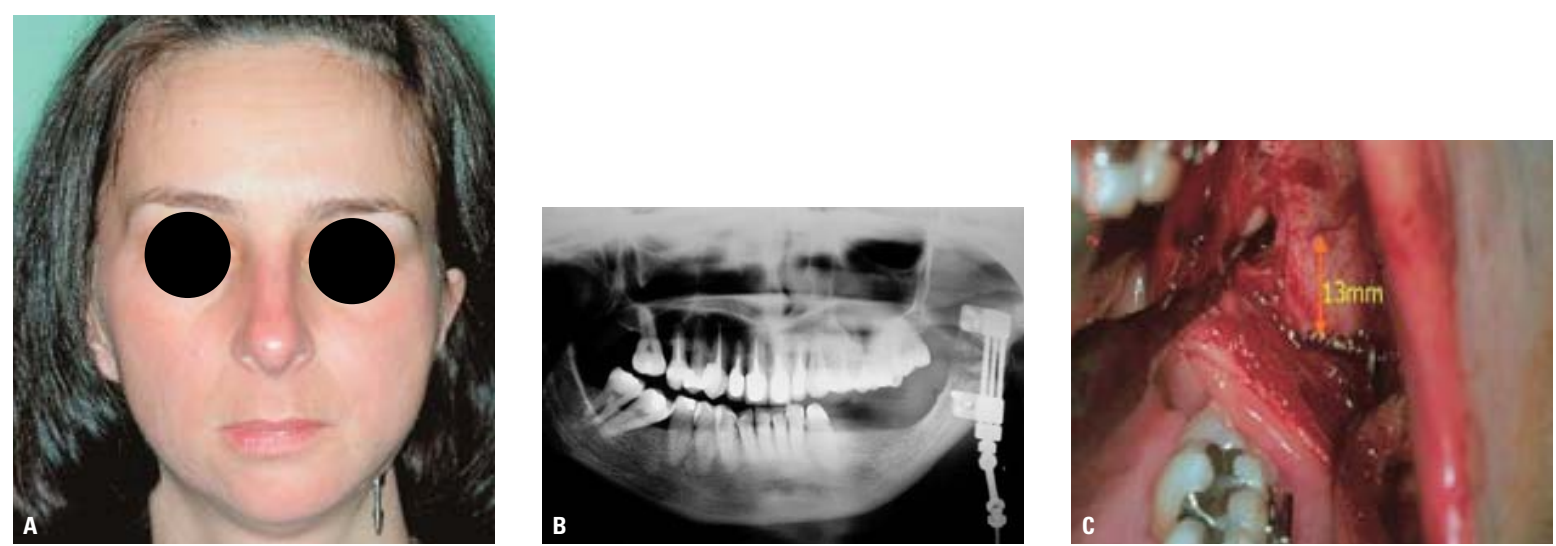

FIGURA 16 - A) Pós-operatório, B) Radiografia panorâmica pós-operatória após o término da ativação do distrator, C) Trans-operatório para remoção do distrator demonstrando 0 aumento de osso do ramo mandibular de $13 \mathrm{~mm}$.

\section{Caso 4}

Paciente B. H., 7 anos de idade, gênero masculino, apresentou-se no consultório encaminhado pelo ortodontista para avaliação da assimetria facial. Ao exame clínico detectou-se desvio da linha média dentária inferior em relação à linha média facial e linha média dentária superior, e desvio do mento para o lado esquerdo (Fig. 17). Foi solicitado exame de tomografia computadorizada em cortes coronais e axiais onde pôde se observar o hipodesenvolvimento do côndilo do lado esquerdo. $\mathrm{O}$ tratamento proposto foi a instalação de um distrator no ramo da mandíbula para a correção da deformidade (Fig. 18A).

Por acesso intrabucal na região da linha oblíqua externa foi exposto o ramo da mandíbula, feita a osteotomia no terço médio do ramo e instalação do aparelho, deixando a ativação por via intrabucal. Após 7 dias de latência iniciou-se a ativação com $0.4 \mathrm{~mm}$ por dia, estendendo por 18 dias. No $6^{\circ}$ dia depois de encerrada a ativação o paciente apresentou-se com novo desvio, que ao exame radiográfico detectamos a quebra do aparelho na sua haste. Nova intervenção foi programada e instalação de novo aparelho foi feita. A grande dificuldade nestas circunstâncias é o tecido osteóide com fibras colágenas que geram grande sangramento. Após 7 dias de latência foi reiniciada a ativação até completar a extensão do distrator (15mm) (Fig. 18B). Após 4 meses foi removido o aparelho (Fig. 19).
Observa-se que a progressão da assimetria se acentua com o término do crescimento, quando se torna mais evidente. A importância de se detectar precocemente a origem da assimetria está diretamente relacionada ao seu prognóstico. Como por exemplo, quando uma hiperplasia condilar é detectada, uma cirurgia de condilotomia alta pode resolver o problema, entretanto, se tratado de modo inapropriado, com o uso de elásticos na região posterior, visando o fechamento da mordida aberta posterior, poderá acarretar em compensação na maxila e no plano oclusal, necessitando posteriormente de uma cirurgia de maxila e mandíbula.

\section{CONCLUSÃO}

A conduta para a correção das assimetrias faciais varia de acordo com a etiologia da deformidade, as áreas afetadas, a idade do paciente. A utilização de exames complementares como radiografias convencionais, tomografia computadorizada, reconstruções tridimensionais e a estereolitografia são fundamentais para a determinação do plano de tratamento. As técnicas cirúrgicas aplicadas são variadas, em função das áreas afetadas e da idade do paciente. Atualmente a distração osteogênica é uma alternativa eficiente no tratamento das assimetrias faciais.

Enviado em: Julho de 2003 Revisado e aceito: Agosto de 2003 

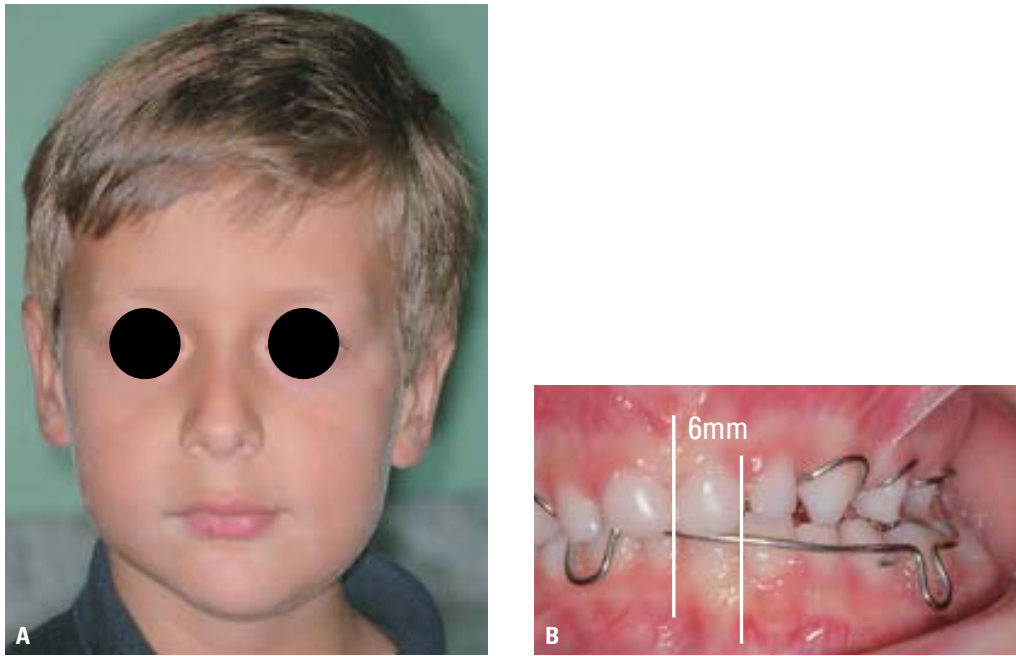

FIGURA 17 - A) Vista frontal, demonstrando assimetria do mento para o lado esquerdo, B) Vista frontal da oclusão evidenciando o desvio de $6 \mathrm{~mm}$ para o lado esquerdo.
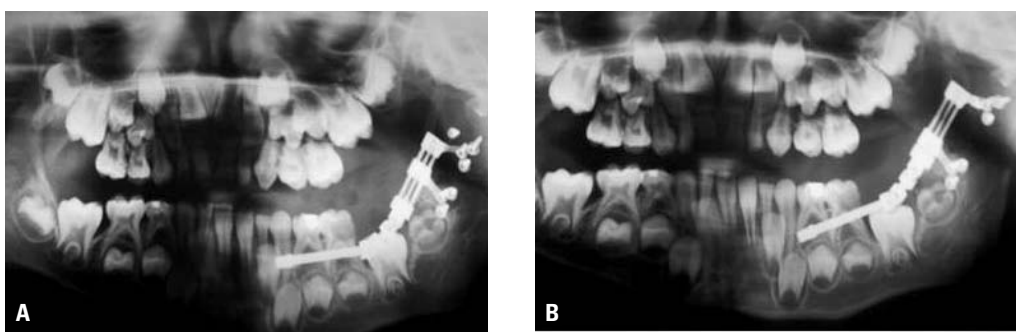

FIGURA 18 - A) Radiografia panorâmica após a instalação do distrator, B) Radiografia panorâmica após conclusão da distração.
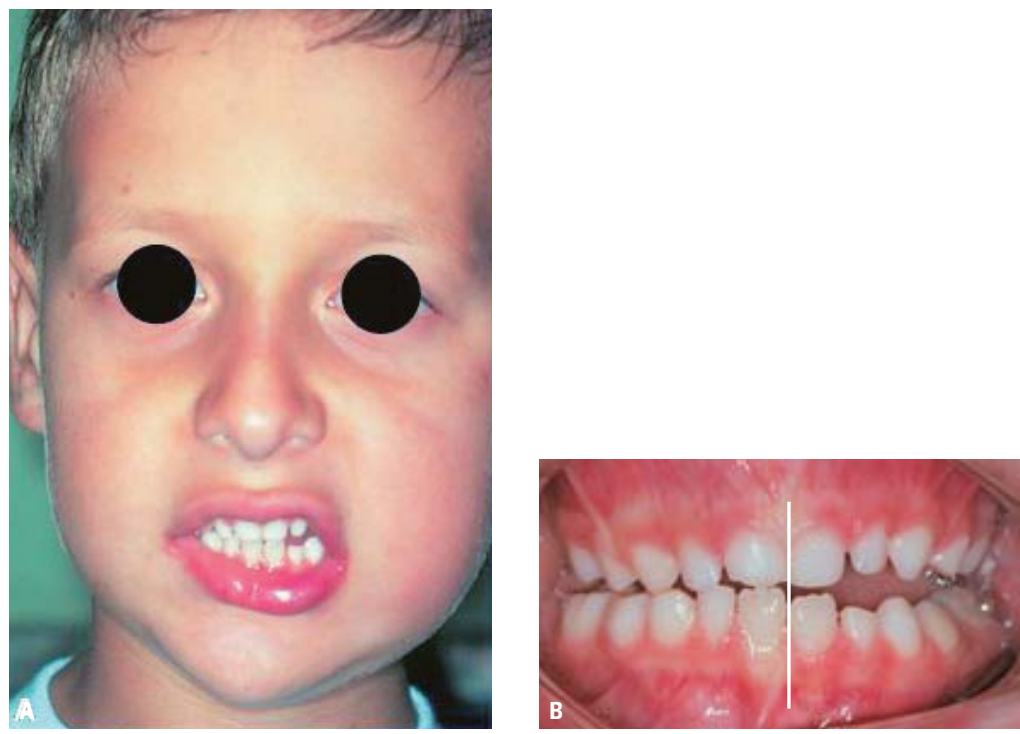

FIGURA 19 - A) Vista frontal da face pós-operatório, B) Vista frontal pós-operatória, corrigindo a linha média observar a mordida aberta posterior que o paciente apresentou. 


\title{
Diagnosis and treatment of dentofacial asymmetry
}

\begin{abstract}
Facial asymmetry is a common human characteristic, which is not notice by the patients themselves many times, not even by those who live with them. The facial asymmetry becomes important when the patient itself relates some alteration. Professional evaluation should be required in order to establish the etiology, through efficient methods of diagnosis. The facial asymmetry can be caused by genetic factors, as found in patients with hemifacial microsomia, or by trauma and pathologies. The treatment for the facial asymmetry has the purpose to bring a satisfactory esthetic result and mainly functional and oclusal stability. The treatment plan is elaborated following the etiology, severity, age and affected areas, correcting the deformity installed or avoiding its progress. The purpose of this study is to review the literature about the etiology, methods of diagnosis and treatment of facials asymmetries, exemplifying with clinical cases the different types of treatment.
\end{abstract}

Key words: Surgery. Facial asymmetry. Treatment.

\section{REFERÊNCIAS}

1. BENSON, K. J.; LASKIN, D. M. Upper lip asymmetry in adults during smiling. J Oral Maxillofac Surg, Philadelphia, v. 59 p. 396-398, 2001.

2. $\mathrm{CHO}$, B. C.; SHIN, D. P.; PARK, J. W.; BAIK, B. S. Bimaxillary osteodistraction for the treatment of facial asymmetry in adults. Br J Plast Surg, Edinburgh, v. 54, p. 491-498, 2001

3. CORCORAN, J.; HUBLI, E. H.; SALYER, K. E. Distraction osteogenesis of costochondral neomandibles: a clinical experience. Plast Reconstr Surg, Baltimore, no. 100, p. 311-315, 1997

4. DAHAN, J. A simple digital procedure to assess facial asymmetry. Am J Orthod Dentofacial Orthop, St. Louis, v. 122, no. 1, p. $110-116,2001$

5. FERRARIO, V. F. et al. The effect of sex and age on facial asymmetry in healthy subjects: a cross-sectional study from adolescence to mid-adulthood. J Oral Maxillofac Surg, Philadelphia, v. 59, p. $382-388,2001$.

6. EPKER, B. N.; FISH, L. C. Dentofacial Deformities. St. Louis: C. V. Mosby, 1986.

7. GUROL, M. et al. Correction of posttraumatic maxillary deficiency by anterolateral alveolar osteotomy. Int J Adult Orthod Orthognath Surg, Chicago, v. 13, no. 4, p. 327-331, 1998.

8. KRAGSKOV, J.; BOSCH, C.; GYLDENSTED, C.; SINDET-PEDERSEN, S. Comparisonos the reliability of craniofacial anatomic landmarks based on cephalometric radiographs and three-dimensional CT scans. Cleft Palate Craniofac J, Pittsburgh, v. 34 no. 2, p. 111-116, 1997

9. KULA, K.; ESMAILNEJAD, A.; HASS, A. Dental arch asymmetry in children with large overjects. Angle Orthod, Appleton, v. 68, no. 1, p. $45-52,1998$.
10. LANDES, C. A. et al. Introduction of a three-dimensional anthropometry of the viscerocranium. Part II: evaluating osseous and soft tissue changes following orthognathic surgery. J Craniomaxillofac Surg, Stuttgart, v. 30, p. 25-34, 2002.

11. MONASTERIO, O. F.; MOLINA, F.; ANDRADE, L.; RODRIGUEZ, C.; ARREGUI, J. S. Simultaneous mandibular and maxillary distraction in hemifacial microsomia in adults: avoiding occlusal disasters. Plast Reconstr Surg, Baltimore, no. 100, p. 852-861, 1997.

12. PEREDA, J. C.; VARELA, M.; PÉREZ, D. M. Preparing a hemimandibulectomy patient for delayed reconstructive surgery. Am J Orthod Dentofacial Orthop, St. Louis, v. 118, p. 572-577, 2000.

13. PETERSON, L. J. et al. Cirurgia oral e maxilofacial contemporânea. 3. ed. Rio de Janeiro: Guanabara Koogan, 2000.

14. PIRTTINIEMI, P. Normal and increased functional asymmetries in the craniofacial area. Acta Odontol Scand, Oslo, v. 56, p. 342 345, 1998.

15. SHAFER, W. G.; HINE, M. K.; LEVY, B. M. Patologia bucal. 3. ed. Rio de Janeiro: Interamericana, 1979. p. 560-573.

16. SJURSEN, R. C.; LEGAN, H. L.; WERTHER, J. R. Case Report: Assessment, documentation, and, treatment of a developing facial asymetry following early chidhood injury. Angle Orthod Appleton, v. 69, no. 1, p. 89-94, 1999.

17. VARGERVIK, K. Mandibular malformations: growth characteristics and management in hemifacial microsomia and Nager syndrome. Acta Odontol Scand, Oslo, v. 56, p. 331-338, 1998.

18. YOON, H. J.; KIM, H. G. Intraoral mandibular distraction osteogenesis in facial asymmetry patients with unilateral temporomandibular joint bony ankylosis. Int J Oral Maxillofac Surg. Copenhagen, v. 31, p. 544-548, 2002.

\author{
Endereço para correspondência \\ João Luiz Carlini \\ Rua Bruno Filgueira, 369 - Cj.1502 \\ Batel - Curitiba - PR \\ CEP: 80240-220 \\ E-mail: joaocarlini@ig.com.br
}

